\title{
Impact of heavy metals pollution on molecular genetics of some medicinal plants
}

\author{
Esraa. A. El Sherbeny ${ }^{1}$ A.A. Morsy ${ }^{2}$ and A.H. Hassan ${ }^{1}$ \\ ${ }^{1}$ Desert Research Center, Ministry of Agriculture, Mataria, Cairo, Egypt \\ ${ }^{2}$ Botany Department, Faculty of Science, Ain Shams University, Cairo, Egypt.
}

\begin{abstract}
Heavy metals are natural constituents of the environment, but indiscriminate use for human purposes has altered their biochemical and molecular genetic balance. Prolonged exposure and higher accumulation of such heavy metals can have deleterious health effects on human life. Impact of heavy metals pollution may be effect on plant in the DNA molecular genetics level. In the present investigation we focus to evaluate the pollution of heavy metals among three plant species from two sites of polluted and non polluted regions based on analysis of molecular genetics level of ISSR, AFLP. Five out of the 10 ISSR primers were HB9, HB10, HB11, HB12 and HB14 which were succeed to amplify 172 reproducible and polymorphic bands on the other hand AFLP analysis also was used depend on pairs of primers EcoR I-ACA and MseI-CTC which provided a total of 116 bands ranging from 1550 to $154 \mathrm{bp}$. Molecular genetics ISSR and AFLP markers appeared more significant differences between polluted and non polluted plants which will provide a new insight for better understanding of the molecular basis of nutritional stress responses of wild medicinal plants to pollution which reflect the genetic defense action and reaction against genetically through appearance some bands product on the transcription and translation level.
\end{abstract}

Keywords: heavy metals pollution, molecular genetic, ISSR, AFLP and wild plants The present research aimed to study the effects of metal pollution stress among three wild plants response on two sites of polluted and non polluted regions and changes in its profile by using molecular analysis, which provides additional information.

\section{Introduction}

Several studies indicate that grain production worldwide should increase in the coming years to sustain the food needs of the growing human population. The world population is expected to reach 10 billion by 2050 . Alkaline and acid soils represent one of the very few options for agricultural expansion for example of abiotic stress. During the two last decades, studies have been conducted to understand the physiological, biochemical adaptive strategies used by plants to grow in acid and alkaline soils. Only recently, developments in molecular biology have resulted in identification, isolation and molecular characterization of genes involved in heavy metal tolerance and nutrient scavenging, which have important implications for improving plant growth by means of transgenic approaches.

Heavy metal stress also is one of the major abiotic stresses that cause environmental pollution effect on plants in recent decades. These metals unlike other organic pollutants are not degraded and converted into harmless compounds via biological processes in plants (Gisbert et al., 2003). Hence, they can persist for a long time in the environment and entry into plant food chain. A common feature of environmental stress is their ability for production of toxic oxygen derivatives (Arora et al., 2002). The transport of heavy metals into plant roots is increased in acid soils. At high concentrations, plant micronutrients such as $\mathrm{Fe}, \mathrm{Mn}, \mathrm{Cu}$ and $\mathrm{Zn}$ and other metals such as $\mathrm{Al}, \mathrm{Cd}, \mathrm{Pb}$ and $\mathrm{Ni}$ for example cause phytotoxic effects, which include reduction of root growth, reduction in chlorophyll content and photosynthesis, inhibition of enzyme activities and damage to chloroplasts and mitochondria. Thus, many plant species have developed genetic tolerance to survive in natural metal-rich soils or in those soils subjected to increasing heavy metal pollution. It is common to find species of Gramineae, Lamiaceae, Fabaceae and Brassicaceae widely distributed throughout heavy-metalcontaminated ecosystems worldwide Herrera-Estrella et al., (1999).

In the present study, we report the application of ISSR markers to the study of plant species with populations adapted to heavy metals, this technique allowed us to show that adaptation to metal-contaminated soils in populations could be associated with a significant reduction in genetic variation Mengoni et al. (2001). On the other hand AFLP markers also play effective role for the molecular genetic analysis for polluted and non polluted plants sites Karp et al. (1997) who reported that AFLP technique is rapidly becoming the method of choice for estimating genetic diversity in both cultivated and natural populations. 
Plant materials

\section{Materials and methods}

Three plant species were used in our study under pollution of heavy metals of cement factory, Alexandria, Borg El Arab and their replicate under non polluted plants.

\begin{tabular}{|r|r|r|}
\hline Scientific name & Family & Location \\
\hline Atrplix halimus & Chenopodioideae & Alexandria, Borg El Arab, \\
Salsola tetrandum & Salsoloideae & Latitude: North, 30 ${ }^{\circ} 52^{\prime} 52.59$ \\
Echinops spinosus & Asteraceae & Longitude: East, 29 29 27 '56.96 \\
\hline
\end{tabular}

\section{Methods \\ DNA extraction}

Extraction of total DNA was performed using methods for medicinal and aromatic plants according to Anna et al. (2001). To remove RNA contamination, RNase A (10 mg/ml, Sigma, USA) was added to the DNA solution and incubated at $37^{\circ} \mathrm{C}$ for $30 \mathrm{~min}$. Estimation of the DNA concentration in different samples was done by measuring optical density at $260 \mathrm{~nm}$ according to the following equation:

Conc. $(\mathrm{ug} / \mathrm{ml})=\mathrm{OD} 260 \times 50 \times$ dilution factor.

Inter simple sequence repeats (ISSRs)

Microsatellite DNA, (simple sequences repeats) which consists of short tandem repeats units 3 to $5 \mathrm{bp}$ in length that repeats. They also had known as variable number of tandem repeats. Microsatellite polymorphism is based on the different numbers of a short repeated motif at a given locus SSRs are becoming the markers of choice in many plant-breeding programs because they are transferable, multiallelic co-dominant markers, PCRbased, easily reproducible, randomly and widely distributed along the genome, and they can be analyzed efficiently by the polymerase chain reaction (PCR), using primers specific to their flanking regions variation in (PCR) product length is a function of the number of SSR units. SSRs have been recommended as standard markers maps. The ISSR marker is simple and has reproducibility. It requires small amounts of DNA and does not require information on DNA sequence. ISSR primers are designed from SSR motifs and can be undertaken for any plant species containing a sufficient number and distribution of SSR motifs in the genome (Gupta et al., 1996; Buhulikar et al., 2004).

Amplified fragment length polymorphisms (AFLPs) AFLP is a technique based on the detection of genomic restriction fragments by PCR amplification and can be used for DNA of any origin or complexity. The fingerprints are produced, without any prior knowledge of sequence, using a limited set of genetic primers. AFLP allows for the selective amplification of restriction fragments from a total digest of genomic DNA and is extremely useful in detection of polymorphism between closely related genotypes.

AFLP procedure was applied according to (Vos et al., 1995). Samples were prepared by cutting the genomic DNA with two restriction enzymes (EcoRI and MseI) and ligating with double stranded EcoR 1and Mse1 adaptors. The adaptors were ligated with the overhanging sticky ends produced by the restriction enzymes.

\section{Statistical data analysis}

The distinct and reproducible molecular data bands for both of ISSR and AFLP were scored as either present (1) or absent (0). The binary data (matrix) was used for calculating Jaccard's coefficient of genetic similarity between all possible pairs of collections. A dendrogram (cluster diagram) was constructed with similarity coefficient using the un weighted pair-group arithmetic averages (UPGMA) procedure of the NTSYSpc program, version 2.1. The confidence limits for the dendrogram groupings were performed by bootstrapping using the Win Boot programme (Yap and Nelson, 1996).

\section{Optimization of ISSR-PCR system and primers screening}

\section{Results and Discussion}

Five out of the 10 ISSR primers amplified reproducible and polymorphic bands which used to study the pollution effect on the molecular level, the results are summarized in (Table 1). The five primers were HB9, HB10, HB11, HB12 and HB14 which succeed to amplified 172 bands of distinct molecular sizes, the number of bands per primer ranged from 22 to 31 with an average of 13 bands per primer. A representative ISSR banding pattern amplified by the primers is presented in Fig 1, also the ISSR molecular data has been revealed some molecular markers bands in contaminated plants and absence in the other non polluted plants which reflect also the molecular genetics action against the heave metal pollution. SPSS computer program was applied. The degree of similarity of ISSR data was represented by similar values, which ranged between $0-1$ for the most dissimilarity and most similar between any given pair of species. To perform and draw the phylogenetic dendrogram SPSS program was applied. The similarity index ranged from 0.32 to 1.0 with a mean similarity of 0.81 , indicating considerable variability detected by ISSR markers. The lowest similarity was observed between 1 and 6 (32\%), and the highest similarity was observed between 1 and 2 with $91 \%$ similarity which was the most 
closely related. The result of the dendrogram was similar although it was observed that two distinct clusters were formed. The polymorphism in presence/absence of ISSR fragments was used to construct a dendogram (Fig 2) based on Jaccard's similarity coefficient. In the present analysis of samples, two major clusters were identified, the first included Atrplix halimus, while the latter included two clusters; one for Salsola tetrandum, while the other for Echinops spinosus.

\section{Identification of AFLP markers}

AFLP analysis using pairs of primers EcoR I- ACA and MseI - CTC provided a total of 116 bands ranging from 1550 to $154 \mathrm{bp}$ (Figure 3). 79 out of 116 bands were polymorphic and 17 of them were monomorphic bands.The pair-wise differences among the polluted three sites and their replicate of non polluted plants were calculated by statistical package for social science (SPSS ver.10) computer program. The analysis was based on the number of markers that can differentiate between any given pair of genotypes or species to calculate the similarity matrix.

Dendrogram SPSS program evaluation

SPSS computer program was applied to calculate the degree of similarity which was represented by similar values, which ranged between $0-1$ for the most dissimilarity and most similar between any given pair of species. To perform and draw the phylogenetic

Sites 3 and 4 were found to be linked together and have closer relationship (84\%) with each other within polluted and non polluted plants. While, sites 1 and 5 were found to be linked together and have not closer relationship (19\%) with each other within polluted and non polluted plants, (Table 3).

Dendrogram was constructed using UPGMA clustering to show the relationships among/between tha two sites of the polluted and non polluted plants (Figure 4). Analysis of genetic similarity within polluted and non polluted plants, ranged from 0.1 to 1.0 .

The similarity index ranged from 0.19 to 1.0 , indicating considerable variability detected by AFLP markers. The lowest similarity was observed between 1 and $5(19 \%)$ and the highest similarity was observed between 3 and 4 with $84 \%$ similarity which was the most closely related. The result of the dendrogram was similar although it was observed among the two distinct clusters of ISSR and AFLP which were formed. The polymorphism in presence/absence of AFLP fragments was used to construct a dendogram (Fig 5) based on Jaccard's similarity coefficient. In the present analysis of samples, two major clusters were identified, the first included Atrplix halimus, while the latter included two clusters one for Salsola tetrandum while the other for Echinops spinosus.

\section{Conclusion}

Molecular genetics studies should complement the morphological and proteomic approaches concerning the effect of heavy metals stress in genetic expression for increased plant resistance to metal stress. The results indicated that the application of ISSR markers to the study of plant species with populations adapted to heavy metals, this technique allowed us to show that adaptation to heavy metal-contaminated in populations could be associated with a significant reduction in genetic variation, this is consistent with Mengoni et al. (2001) chloroplast microsatellite analysis showing a large reduction in genetic diversity associated with Silene paradoxa populations growing in copper-contaminated soils also agreed with Pharmawati et al. (2005) who was reported that 17 out of 584 ISSR markers were found to be cultivar-specific markers among 30 Leucadendron cultivars. In addition, it was also agreed with Abdel-Tawab et al. (2007) showed that 48 out of 164 ISSR markers were specific markers among seven genotypes of Ocimum species using 10 ISSR primers. In general, the ISSR-PCR was efficient in discriminating among the polluted and non polluted plants under investigation.

On the other hand, results indicated that AFLP markers gave also adequate distinctions among the polluted and non polluted plants sites, these results agreed also with those Karp et al. (1997) who reported that AFLP technique is rapidly becoming the method of choice for estimating genetic diversity in both cultivated and natural populations. Neqi et al. (2000) also used AFLP markers to study inter- and intraspecific genetic variations using 35 individuals of Withania somnifera and five individuals of $\mathrm{W}$. coagulans which is an important wild medicinal plants, they suggested that AFLP marker is as an efficient tool for estimating genetic similarity in plant species and effective management of genetic resources among the polluted and non polluted plants sites.Bands of DNA markers on the molecular genetics level were successfully to identify the pollution effect based on the techniques of molecular ISSR and AFLP which were succeed to have great relevance on taxonomic studies for pollution stress.Conservationist may use the genetics molecular markers bands information of the present study to make effective decisions regarding the global protection and management from polluted and non polluted plants in Egypt, which lead us to understand and conclude the genetics translation defense against pollution by increasing transcription and translation rate during pollution stress through coding some resist genes against pollution action as defense pathway. 
In general, the appropriate timeframe for sampling genetic diversity to detect meaningful changes will vary according to species and to the environment (Gupta et al., 1996). Most of population sites were mining areas well known for the severity of environmental degradation, it is established that the long lived the species and the longer the time to reproductive maturity, the longer it will take in absolute time to detect genetic changes in such environment therefore it was expected that heavy metal tolerant herbaceous species are likely to exhibit changes in gene expression than conifer tree populations growing in contaminated areas.In finally, monitoring the genetic diversity of populations has been useful in detecting trends that should alert ecologists to potential problems of large loss in diversity such as in Cobalt areas could have negative effects on fitness and survival in long term and the ability to changing environmental conditions.

Table (1): ISSR primer data and the percentage of polymorphic bands.

\begin{tabular}{|l|l|l|l|l|l|l|}
\hline Primer & 5'-3' sequence & $\begin{array}{l}\text { Number of } \\
\text { monomorphic } \\
\text { bands }\end{array}$ & $\begin{array}{l}\text { Number of } \\
\text { unique } \\
\text { bands }\end{array}$ & $\begin{array}{l}\text { Number of } \\
\text { polymorphic } \\
\text { bands }\end{array}$ & $\begin{array}{l}\text { Total bands } \\
\text { amplified }\end{array}$ & $\begin{array}{l}\text { Polymorphism } \\
(\%)\end{array}$ \\
\hline HB9 & $(\mathrm{GT})_{6}$ GG & 0 & 9 & 13 & 22 & 100 \\
\hline HB10 & $(\mathrm{GA})_{6}$ CC & 2 & 3 & 18 & 23 & 91.3 \\
\hline HB11 & $(\mathrm{GT})_{6}$ CC & 0 & 11 & 20 & 31 & 100 \\
\hline HB12 & $(\mathrm{CAC})_{3}$ GC & 0 & 10 & 19 & 29 & 100 \\
\hline HB14 & $(\mathrm{CTC})_{3}$ GC & 2 & 7 & 16 & 25 & 92 \\
\hline
\end{tabular}
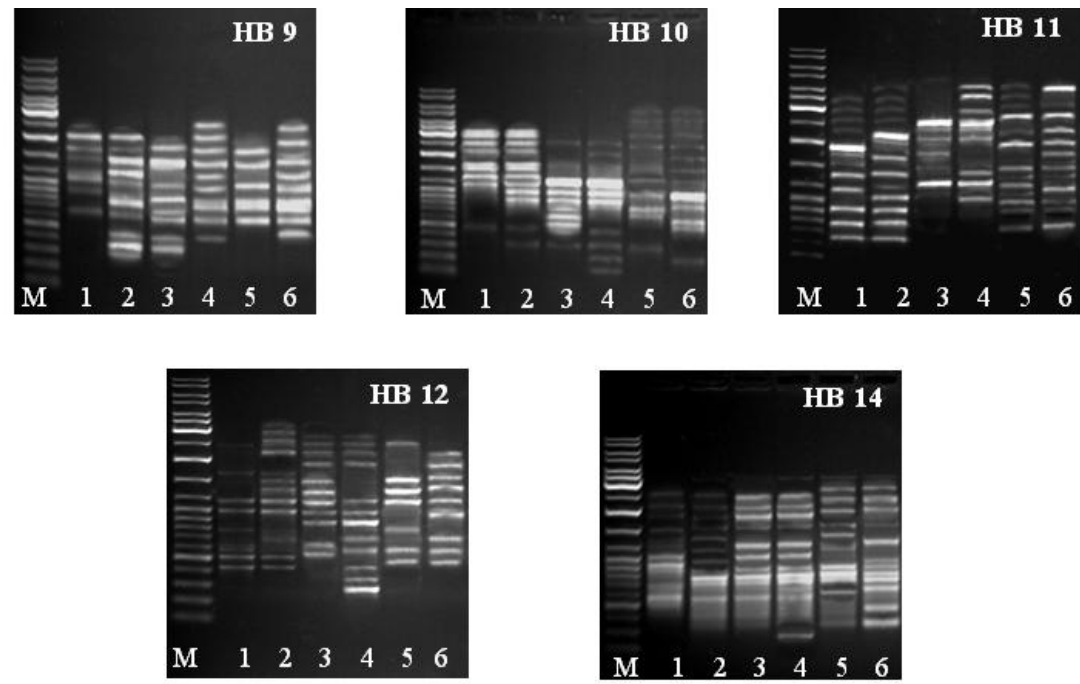

Figure (1). ISSR electrophoresis patterns of the primers HB9, HB10, HB11, HB12 and HB14. Lane M DNA marker; lanes 1-6 are identified in Table 1.

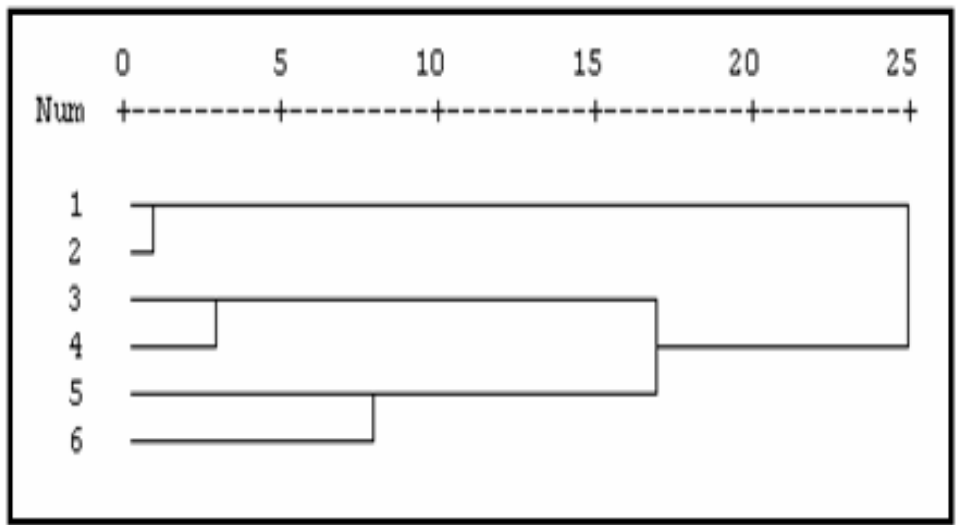

Figure (2). Dendrogram based on (UPGMA) method between polluted and non polluted plants based on ISSR data. 


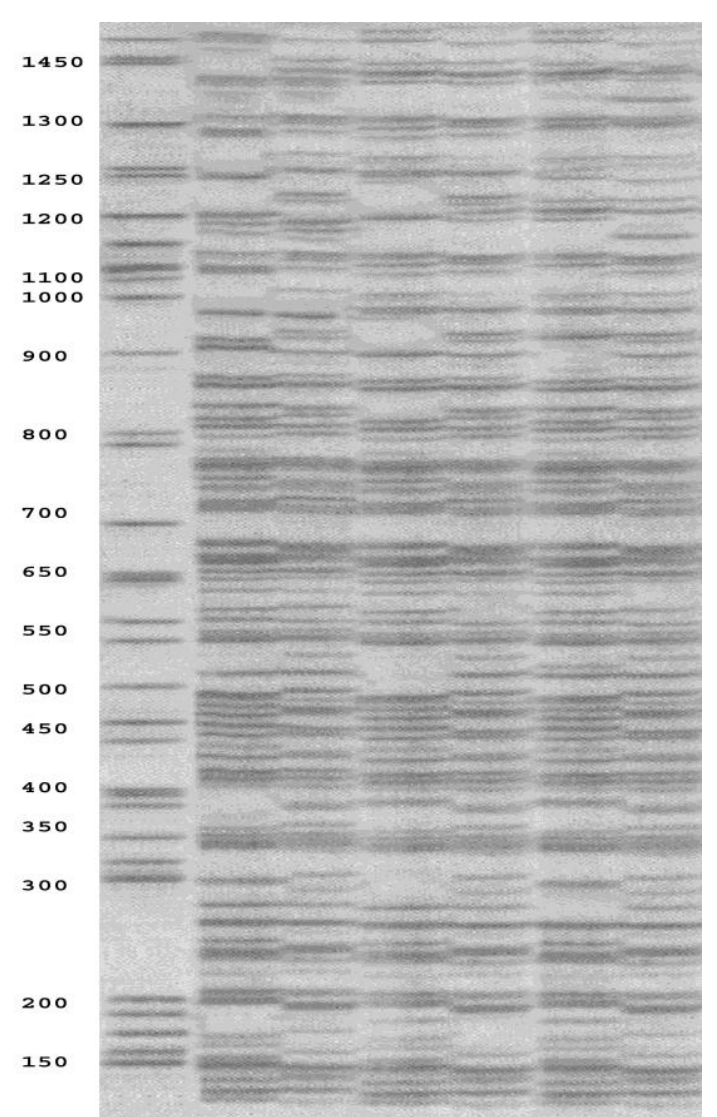

Figure (3): AFLP profiles between polluted and non polluted plants

Table (2). Similarity matrixes between polluted and non polluted plants based on ISSR data .

\begin{tabular}{|l|l|l|l|l|l|l|}
\hline & 1 & 2 & 3 & 4 & 5 & 6 \\
\hline 1 & 1.000 & & & & & \\
\hline 2 & .916 & 1.000 & & & & \\
\hline 3 & .506 & .519 & 1.000 & & & \\
\hline 4 & .485 & .404 & .832 & 1.000 & & \\
\hline 5 & .383 & .422 & .513 & .589 & 1.000 & \\
\hline 6 & .323 & .344 & .526 & .585 & .850 & 1.000 \\
\hline
\end{tabular}

Table (3). Similarity matrixes between polluted and non polluted plants. based on AFLP data .

\begin{tabular}{|l|l|l|l|l|l|l|}
\hline & 1 & 2 & 3 & 4 & 5 & 6 \\
\hline 1 & 1.000 & & & & & \\
\hline 2 & .514 & 1.000 & & & & \\
\hline 3 & .615 & .402 & 1.000 & & & \\
\hline 4 & .313 & .559 & .840 & 1.000 & & \\
\hline 5 & .198 & .397 & .548 & .294 & 1.000 & \\
\hline 6 & .438 & .434 & .566 & .731 & .672 & 1.000 \\
\hline
\end{tabular}

$\begin{array}{llllll}0 & 5 & 10 & 15 & 20 & 25\end{array}$
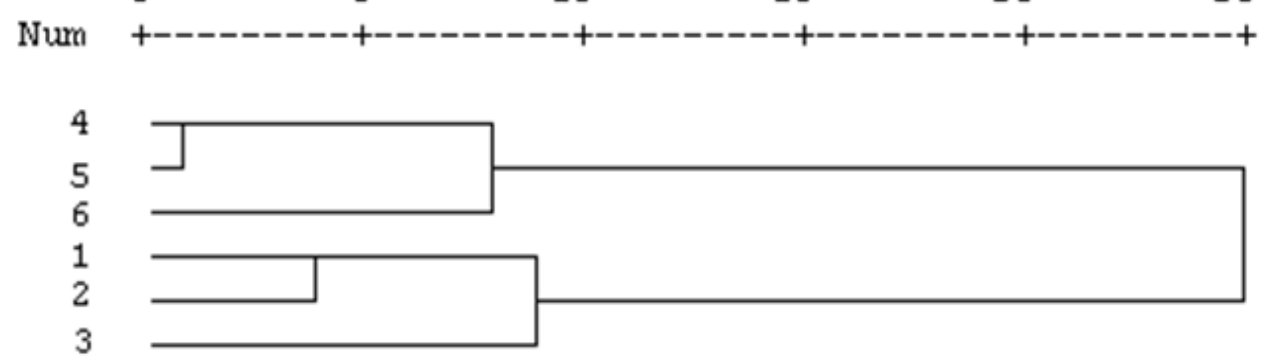

Figure (4). Dendrogram based on (UPGMA) method between polluted and non polluted plants based on AFLP data. 
Table (4). Similarity matrixes between polluted and non polluted plant based on ISSR $\mid \&$ AFLP data.

\begin{tabular}{|l|l|l|l|l|l|l|}
\hline & 1 & 2 & 3 & 4 & 5 & 6 \\
\hline 1 & 1.000 & & & & & \\
\hline 2 & .817 & 1.000 & & & & \\
\hline 3 & .252 & .533 & 1.000 & & & \\
\hline 4 & .230 & .314 & .305 & 1.000 & & \\
\hline 5 & .461 & .399 & .498 & .608 & 1.000 & \\
\hline 6 & .167 & .328 & .584 & .367 & .751 & 1.000 \\
\hline
\end{tabular}
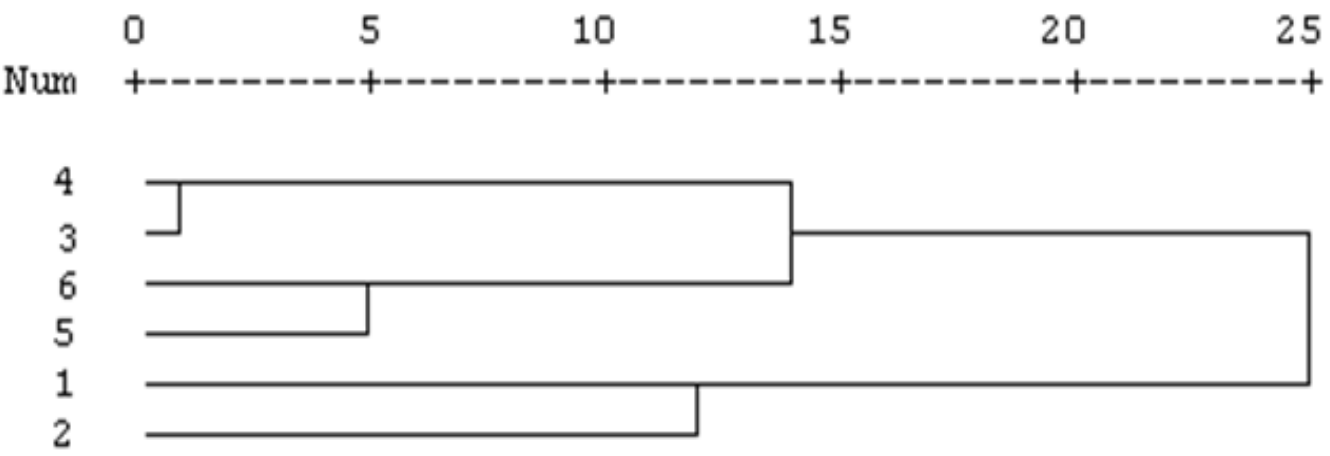

Figure (5). Dendrogram based on (UPGMA) method between polluted and non polluted plants based on ISSR\& AFLP data.

\section{References}

[1]. Abdel-Tawab, F.M., Eman M. Fahmy, Hoda M. EL-demerdash, O. M. saleh, H. fotouh and GH. A. gad EL-karim(2007). Molecular phylogenetic relationships of two genera of labiatae family. Egypt. J. Genet. Cytol., 36(2): 325-339.

[2]. Arora, A.; Sairam, R.K.; Srivastave, G.C. Oxidative stress and antioxidative systems in plants. Curr. Sci. 2002, 82, $1227-1238$.

[3]. Anna M.P., Hirsikorpi M, Kämäräinen T, Jaakola L, Hohrola A (2001). DNA isolation methods for medicinal and aromatic plants. Plant Mol.Biol. Rep., 19: 273a-f.

[4]. Buhulikar RA, Stanculescu D, Preston CA, Baldwin IT (2004). ISSR and AFLP analyses of the temporal and spatial population structure of the post-fire annual Nicotiana attenuate in SW, Utah. BMC Ecol., 4: 1-13.

[5]. Gisbert C, Ros R, de Haro A, Walker DJ, Pilar Bernal M, Serrano R, Avino JN. (2003). A plant genetically modified that accumulates $\mathrm{Pb}$ is especially promising for phytoremediation. Biochem Biophys Res Commun. 303(2):440-445.

[6]. Gupta PK, Balyan HS, Sharma PC and Ramesh B (1996) Microsatellites in plants: a new class of molecular markers. Curr Sci 70: 45-54.

[7]. Herrera-Estrella, L., Guevara-García, A., and López-Bucio, J.: Heavy metal adaptation. Encyclopedia of Life Science Macmillian Publishers, London, UK, 1-5, 1999.

[8]. Karp, A., K. Edwards, M. Bruford, B. Vosman, M. Morgante, O. Seberg, A. Kremer, P. Boursot, P. Arctander, D. Tautz and G. Hewitt (1997). Newer molecular technologies for biodiversity evaluation: Opportunities and challenges. Nature Biotechnol15:625628 .

[9]. Mengoni, A., Barabesi, C, Gonnelli, C., Galardi, F., Gabbrielli, R., and Bazzicalupo, M. (2001) Genetic diversity of heavy metaltolerant populations in Silene paradoxa (Caryophyllaceae): a chloroplast microsatellite analysis. Mol. Ecology 10: 1909-1916.

[10]. Neqi, M.S., A. singh, and Lakshmikumaran (2000). Genetic variation and relationship among and within Withania species as revealed by AFLP markers. Genome. 2000 Dec;43(6):975-80.

[11]. Pharmawati, M., G.Yan and P.M. Finnegan (2005).Molecular variation and fingerprinting of Leucadendron cultivars (proteaceae) by ISSR markers. Ann. Bot. (Lond), 7: 11(63-1170.

[12]. Vos, P., R. Rogers, M. Bleeker, M. Reijans, T. Van de Lee, M. Hornes, A. Fijters, J. Pot, J. Peleman, M. Kuiper and M. Zabeau (1995). AFLP, a new technique for DNA fingerprinting. Nucleic Acids Res., 23: 4407-4414.

[13]. Yap, I. V. \& Nelson, R. J. (1996) WinBoot : a program for performing bootstrap analysis of binary data to determine the confidence limits of UPGMA-based dendrograms. [IRRI Discussion Paper Series No. 14.] International Rice Research Institute, Manila. 